\section{Perfil epidemiológico da violência física intrafamiliar: agressões denunciadas em um município do Estado de São Paulo, Brasil, entre 2001 e 2005}

\author{
Epidemiological profile of domestic violence: \\ complaints of aggression filed in a city in \\ São Paulo State, Brazil, from \\ 2001 to 2005
}

\section{${ }^{1}$ Faculdade de Odontologia de Araçatuba, Universidade Estadual Paulista, Araçatuba Brasil. \\ Correspondência C. A. S. Garbin Departamento de Odontologia Infantil e Social, Faculdade de Odontologia de Araçatuba, Universidade Estadual Paulista. Rua José Bonifácio 1193. Araçatuba, SP 16015-050, Brasil. cgarbin@foa.unesp.br}


Com a finalidade de melhorar o acolhimento institucional e incentivar as denúncias de violência doméstica, foram criadas as Delegacias de Defesa da Mulher na década de 1980. O Brasil foi pioneiro na implantação deste serviço que hoje é desenvolvido em outras partes do mundo ${ }^{2}$. Apesar do nome referir-se especificamente à "mulher", estas unidades são competentes para receber ocorrências e apurar crimes de natureza familiar, independentemente de gênero.

Mesmo sendo o número de casos registrados infinitamente menor do que o ocorrido, a criação das delegacias especializadas proporcionou uma maior visibilidade à questão, constituindo importantes "fontes de dados" que certamente podem contribuir para o planejamento de ações específicas nesta área.

Infelizmente, não são muitos os estudos de caráter epidemiológico que se propõem a explorar esses dados, talvez pela dificuldade em coletá-los ou pelo receio gerado pelo ambiente das delegacias, fato este que torna ainda mais relevante a realização da presente pesquisa.

Deste modo, torna-se possível traçar o perfil tanto da vítima quanto de seu agressor, mesmo que este se limite aos casos registrados pelas ocorrências policiais. Tais informações podem ajudar a compreender as circunstâncias em que ocorreu a violência, contribuindo para a prevenção e enfrentamento do problema.

O objetivo geral deste estudo consistiu em determinar o perfil epidemiológico da agressão familiar física registrada na Delegacia de Defesa da Mulher de Araçatuba, São Paulo, Brasil, no período compreendido entre os anos de $2001 \mathrm{e}$ 2005. Especificamente, teve como propósito: determinar as relações de parentesco entre agressores e vítimas; analisar as agressões quanto ao dia, horário e local de maior ocorrência; verificar os motivos atribuídos às agressões e o envolvimento de bebida alcoólica e drogas ilícitas nos atos violentos e; descrever o perfil sócio-demográfico de agressores e vítimas e as características das lesões.

\section{Métodos}

Este estudo caracterizou-se como descritivo e contou com a aprovação do Comitê de Ética em Pesquisa da Faculdade de Odontologia de Araçatuba, da Universidade Estadual Paulista, processo $n^{\circ}$. 2005-01861. Foram analisados todos os 7.750 inquéritos policiais e termos circunstanciados efetuados pela única Delegacia de Defesa da Mulher, na cidade de Araçatuba, no período de janeiro de 2001 a dezembro de 2005. Destes, foram incluídos na amostra somente os que eram procedentes de agressões físicas, ocorridas em qualquer ambiente, provocadas por pessoa com quem a vítima mantém ou manteve relacionamento familiar, totalizando 1.844 prontuários, sendo, portanto, excluídos os outros 5.906 registros por não atenderem aos critérios de inclusão citados acima. Não foram excluídos prontuários por imprecisão dos dados constantes na ocorrência, sendo que diante da ausência de informações nos mesmos, essas foram anotadas pelos pesquisadores no item nomeado como "sem informação".

Os documentos analisados foram termos circunstanciados e inquéritos policiais. Façamos então uma distinção entre eles.

O termo circunstanciado foi instituído pela Lei $n^{\circ} .9 .099$ de $1995^{3}$, que dispõe sobre os Juizados Especiais Criminais. Constitui o registro do caso, porém de uma maneira mais completa que o boletim de ocorrência. É empregado em crimes de menor potencial ofensivo, ou seja, naqueles onde a pena máxima não ultrapassa dois anos 4, como por exemplo, a lesão corporal leve.

Inquérito policial é todo procedimento policial destinado a reunir elementos necessários à apuração da prática de uma infração penal e de sua autoria 4 .

As informações foram coletadas por meio de um formulário elaborado pelos pesquisadores. Durante a coleta dos dados os autores não tiveram acesso aos nomes de agressores e vítimas. A autoridade policial competente providenciou para que a identidade das partes fosse preservada, uma vez que se trata de casos familiares e, por conseqüência, o acesso aos referidos documentos é restrito. Justamente por isso, não se pode afirmar que as denúncias foram feitas por pessoas distintas ou se existiram casos de reincidência.

As características analisadas foram: agressão; características sócio-demográficas de agressores e vítimas; e laudo médico.

- Agressão: horário, dia da semana, local da ocorrência, motivo, relação vítima-agressor e presença de drogas durante o ato. O parentesco vítima-agressor foi classificado em três grupos, sendo o primeiro (grupo A) composto por relações entre casais (cônjuges, companheiros, namorados etc.), o segundo (grupo B) entre responsáveis (pais/responsáveis, padrastos, madrastas) e filhos, e o terceiro (grupo C) entre os demais familiares (irmãos, primos, cunhados etc.). Quando bebida alcoólica ou drogas são mencionadas nas denúncias, significa que agressor estava sob efeito de álcool ou drogas ilícitas no momento da agressão.

- Características sócio-demográficas de agressores e vítimas: gênero, idade, estado civil, esco- 
laridade, ocupação. No referente à ocupação da vítima e do agressor, foi utilizada a Classificação Brasileira das Ocupações (CBO) do ano de 2002 5, para o agrupamento das mesmas (Tabela 1). Para as ocupações não descritas na referida classificação, utilizou-se o termo "outras".

Os grupos 7, 8 e 9 reservam-se aos trabalhadores que fabricam bens, operam e mantêm equipamentos, sejam eles estacionários ou móveis (por exemplo, veículos). Os grupos 7 e 8, mesmo redigidos da mesma maneira, possuem finalidades distintas, conforme a CBO de 2002 5. Assim, no grupo 7 constam os trabalhadores de sistemas de produção que lidam mais com a forma do produto do que com o seu conteúdo físico-químico. Já no grupo 8 estão elencados os trabalhadores de sistemas de produção que são ou tendem a ser contínuos (química, siderurgia, dentre outros) 5 . - Laudo médico: descrição do tipo, local e classificação legal das lesões, e procura por prontosocorro.

Finda a etapa de coleta, os dados foram digitados e tabulados no programa Epi Info 2000, versão 6.04 (Centers for Disease Control and Prevention, Atlanta, Estados Unidos).

\section{Resultados}

A Tabela 1 apresenta as características gerais das ocorrências, onde podemos destacar quanto à relação autor-vítima, que $1.496(81,1 \%)$ agressões ocorreram entre casais, $213(11,6 \%)$ entre pais/responsáveis e filhos, e 135 (7,3\%) entre outros familiares. Os dados da Tabela 2 também demonstram: (1) a maior freqüência de agressões entre casais (grupo A) nos finais de semana, sem que este padrão se repita nas agressões entre pais e filhos (grupo B); (2) maior freqüência de agressões em casa, no período das 12:00 às 24:00 horas nos três grupos; (3) o atual companheiro sendo o agressor mais freqüente no grupo $\mathrm{A}$, e os pais, os agressores mais freqüentes no grupo $\mathrm{B}$, salientando que em mais de um quinto dos casos desse grupo foram os filhos que agrediram os pais/responsáveis, enquanto no grupo $\mathrm{C}$ prevaleceram as agressões entre irmãos; e (4) nos três grupos, cerca de um quarto a um quinto dos agressores estavam alcoolizados no momento da agressão.

Quanto à agressão entre casais (Tabela 3), $98,3 \%$ dos agressores foram homens, enquanto $98,7 \%$ das vítimas foram mulheres. Entretanto, ocorreram casos de vítimas do gênero masculino $(1,3 \%)$ e agressores do gênero feminino $(1,7 \%)$. Ainda observando os dados da Tabela 3, podese salientar os seguintes pontos: (1) quando os agressores são homens e as vítimas são mulheres, há o dobro de solteiros em relação aos casados e predomina a faixa etária mais jovem (20-34 anos); (2) quando os agressores são mulheres e as vítimas são homens, há uma proporção semelhante de casadas e solteiras entre as mulheres e um predomínio de casados entre os homens, sendo as mulheres mais freqüentemente jovens (20-34 anos) e os homens com idade variando entre 20-59 anos (porcentagem semelhante nas faixas etárias 20-34 anos, 25-44 anos e 45-59 anos); (3) existiam uniões afetivas de pessoas do mesmo sexo, motivo pelo qual o número de agressores do sexo masculino não coincide com o número de vítimas do sexo feminino, assim como o número de agressores do sexo feminino não coincide com o número de vítimas do sexo

Tabela 1

Classificação Brasileira das Ocupações, segundo o Ministério do Trabalho e Emprego 5. Brasil, 2002.

\begin{tabular}{ll}
\hline Grupo & \\
\hline 0 & Forças armadas, policiais e bombeiros militares \\
1 & Membros do poder público, dirigentes de organizações de interesse público e de empresas \\
& e gerentes \\
2 & Profissionais das ciências e das artes \\
3 & Técnicos de nível médio \\
5 & Trabalhadores de serviços administrativos \\
6 & Trabalhadores dos serviços, vendedores do comércio em lojas e mercados \\
7 & Trabalhadores agropecuários, florestais, da caça e pesca \\
9 & Trabalhadores da produção de bens e serviços industriais \\
\hline
\end{tabular}


Tabela 2

Características das 1.844 agressões familiares físicas registradas em termos circunstanciados e inquéritos policiais na Delegacia de Defesa da Mulher de Araçatuba, São Paulo, Brasil, entre 2001 e 2005, segundo grupos de parentesco.

\begin{tabular}{|c|c|c|c|c|c|c|}
\hline \multirow[t]{2}{*}{ Características } & \multicolumn{2}{|c|}{ Grupo A $(n=1.496)$} & \multicolumn{2}{|c|}{ Grupo $B(n=213)$} & \multicolumn{2}{|c|}{ Grupo $C(n=135)$} \\
\hline & $\mathrm{n}$ & $\%$ & $\mathrm{n}$ & $\%$ & $\mathrm{n}$ & $\%$ \\
\hline \multicolumn{7}{|l|}{ Dia da semana } \\
\hline Domingo & 319 & 21,3 & 37 & 17,4 & 28 & 20,7 \\
\hline Segunda-feira & 187 & 12,5 & 38 & 17,8 & 20 & 14,8 \\
\hline Terça-feira & 181 & 12,2 & 34 & 15,9 & 20 & 14,8 \\
\hline Quarta-feira & 190 & 12,7 & 31 & 14,5 & 13 & 9,7 \\
\hline Quinta-feira & 188 & 12,5 & 28 & 13,2 & 18 & 13,3 \\
\hline Sexta-feira & 167 & 11,2 & 26 & 12,3 & 15 & 11,2 \\
\hline Sábado & 264 & 17,6 & 19 & 8,9 & 21 & 15,5 \\
\hline \multicolumn{7}{|l|}{ Horário } \\
\hline 00:01-06:00 & 240 & 16,0 & 15 & 7,1 & 9 & 6,7 \\
\hline 06:01-12:00 & 216 & 14,5 & 33 & 15,5 & 23 & 17,1 \\
\hline 12:01-18:00 & 356 & 23,8 & 90 & 42,2 & 47 & 34,8 \\
\hline $18: 01-24: 00$ & 684 & 45,7 & 75 & 35,2 & 56 & 41,4 \\
\hline \multicolumn{7}{|l|}{ Local } \\
\hline Residência & 1.246 & 83,2 & 201 & 94,4 & 122 & 90,3 \\
\hline Via pública & 200 & 13,4 & 10 & 4,6 & 10 & 7,4 \\
\hline Estabelecimento comercial & 50 & 3,4 & 2 & 1,0 & 3 & 2,3 \\
\hline \multicolumn{7}{|l|}{ Relação familiar } \\
\hline Cônjuge & 349 & 23,3 & 0 & 0,0 & 0 & 0,0 \\
\hline Ex-cônjuge & 94 & 6,3 & 0 & 0,0 & 0 & 0,0 \\
\hline Companheiro(a) & 669 & 44,7 & 0 & 0,0 & 0 & 0,0 \\
\hline Ex-companheiro(a) & 211 & 14,2 & 0 & 0,0 & 0 & 0,0 \\
\hline Namorado(a) & 70 & 4,7 & 0 & 0,0 & 0 & 0,0 \\
\hline Ex-namorado(a) & 103 & 6,8 & 0 & 0,0 & 0 & 0,0 \\
\hline Pai & 0 & 0,0 & 75 & 35,2 & 0 & 0,0 \\
\hline Mãe & 0 & 0,0 & 50 & 23,4 & 0 & 0,0 \\
\hline Padrasto/Madrasta & 0 & 0,0 & 40 & 18,8 & 0 & 0,0 \\
\hline Filho(a) & 0 & 0,0 & 48 & 22,6 & 0 & 0,0 \\
\hline Irmã(o) & 0 & 0,0 & 0 & 0,0 & 68 & 50,3 \\
\hline Tio(a) & 0 & 0,0 & 0 & 0,0 & 17 & 12,5 \\
\hline Avós & 0 & 0,0 & 0 & 0,0 & 14 & 10,4 \\
\hline Primo(a) & 0 & 0,0 & 0 & 0,0 & 13 & 9,7 \\
\hline Cunhado(a) & 0 & 0,0 & 0 & 0,0 & 15 & 11,2 \\
\hline Outros & 0 & 0,0 & 0 & 0,0 & 8 & 5,9 \\
\hline \multicolumn{7}{|l|}{ Motivo atribuído à agressão } \\
\hline Conflitos conjugais íntimos & 15 & 1,0 & 0 & 0,0 & 3 & 2,2 \\
\hline Ciúme & 322 & 21,5 & 3 & 1,5 & 1 & 0,8 \\
\hline Desentendimento & 655 & 43,7 & 131 & 61,5 & 85 & 62,9 \\
\hline \multicolumn{7}{|l|}{ Motivo atribuído à agressão } \\
\hline Dinheiro/Bens & 175 & 11,8 & 22 & 10,3 & 34 & 25,1 \\
\hline Filhos & 115 & 7,7 & 1 & 0,5 & 1 & 0,8 \\
\hline Sem motivo aparente & 214 & 14,3 & 56 & 26,2 & 11 & 8,2 \\
\hline \multicolumn{7}{|l|}{ Bebida alcoólica * } \\
\hline Não & 1.095 & 73,2 & 167 & 78,4 & 112 & 82,9 \\
\hline Sim & 401 & 26,8 & 46 & 21,6 & 23 & 17,1 \\
\hline \multicolumn{7}{|l|}{ Drogas ilícitas ** } \\
\hline Não & 1.463 & 97,8 & 209 & 98,2 & 129 & 95,5 \\
\hline Sim & 33 & 2,2 & 4 & 1,8 & 6 & 4,5 \\
\hline
\end{tabular}

* O agressor estava sob efeito de bebida alcoólica no momento da agressão;

** $\mathrm{O}$ agressor estava sob efeito de drogas no momento da agressão. 
Características de agressores e vítimas envolvidos em agressões familiares físicas (grupo $A ; n=1.496$ ) registradas em termos circunstanciados e inquéritos policiais na Delegacia de Defesa da Mulher de Araçatuba, São Paulo, Brasil, entre 2001 e 2005, segundo o gênero.

\begin{tabular}{|c|c|c|c|c|c|c|c|c|}
\hline \multirow[t]{3}{*}{ Características } & \multicolumn{4}{|c|}{ Agressores } & \multicolumn{4}{|c|}{ Vítimas } \\
\hline & \multicolumn{2}{|c|}{ Masculino $(n=1.471)$} & \multicolumn{2}{|c|}{ Feminino $(n=25)$} & \multicolumn{2}{|c|}{ Masculino $(n=20)$} & \multicolumn{2}{|c|}{ Feminino $(n=1.476)$} \\
\hline & $\mathrm{n}$ & $\%$ & $\mathrm{n}$ & $\%$ & $\mathbf{n}$ & $\%$ & $\mathrm{n}$ & $\%$ \\
\hline \multicolumn{9}{|l|}{ Faixa etária (anos) } \\
\hline $12-19$ & 36 & 2,5 & 1 & 4,0 & 2 & 10,0 & 120 & 8,2 \\
\hline $20-34$ & 819 & 55,6 & 16 & 64,0 & 6 & 30,0 & 870 & 58,9 \\
\hline $35-44$ & 381 & 25,9 & 5 & 20,0 & 6 & 30,0 & 345 & 23,3 \\
\hline $45-59$ & 160 & 10,8 & 2 & 8,0 & 5 & 25,0 & 128 & 8,6 \\
\hline 60 ou mais & 34 & 2,4 & 0 & 0,0 & 1 & 5,0 & 11 & 0,8 \\
\hline Sem informação & 41 & 2,8 & 1 & 4,0 & 0 & 0,0 & 2 & 0,2 \\
\hline \multicolumn{9}{|l|}{ Estado civil } \\
\hline Casado & 421 & 28,6 & 10 & 40,0 & 10 & 50,0 & 414 & 28,0 \\
\hline Solteiro & 807 & 54,8 & 11 & 44,0 & 6 & 30,0 & 817 & 55,3 \\
\hline Separado/Divorciado & 200 & 13,6 & 3 & 12,0 & 4 & 20,0 & 203 & 13,8 \\
\hline Viúvo & 7 & 0,5 & 0 & 0,0 & 0 & 0,0 & 28 & 1,9 \\
\hline Sem informação & 36 & 2,5 & 1 & 4,0 & 0 & 0,0 & 14 & 1,0 \\
\hline \multicolumn{9}{|l|}{ Escolaridade } \\
\hline Analfabeto & 12 & 0,9 & 0 & 0,0 & 1 & 5,0 & 11 & 0,8 \\
\hline Fundamental incompleto & 371 & 25,2 & 5 & 20,0 & 2 & 10,0 & 334 & 22,6 \\
\hline Fundamental completo & 142 & 9,6 & 2 & 8,0 & 1 & 5,0 & 161 & 10,9 \\
\hline Médio incompleto & 60 & 4,1 & 0 & 0,0 & 2 & 10,0 & 101 & 6,8 \\
\hline Médio completo & 70 & 4,8 & 2 & 8,0 & 2 & 10,0 & 162 & 10,9 \\
\hline Superior incompleto & 11 & 0,8 & 1 & 4,0 & 0 & 0,0 & 15 & 1,1 \\
\hline Superior completo & 29 & 1,9 & 0 & 0,0 & 0 & 0,0 & 24 & 1,7 \\
\hline Sem informação & 776 & 52,7 & 15 & 60,0 & 12 & 60,0 & 668 & 45,2 \\
\hline \multicolumn{9}{|l|}{ Ocupação } \\
\hline Grupo 0 & 12 & 0,9 & 0 & 0,0 & 1 & 5,0 & 1 & 0,2 \\
\hline Grupo 1 & 95 & 6,4 & 0 & 0,0 & 1 & 5,0 & 46 & 3,2 \\
\hline Grupo 2 & 40 & 2,7 & 0 & 0,0 & 0 & 0,0 & 37 & 2,5 \\
\hline Grupo 3 & 40 & 2,7 & 4 & 16,0 & 1 & 5,0 & 69 & 4,6 \\
\hline Grupo 4 & 15 & 1,1 & 2 & 8,0 & 0 & 0,0 & 46 & 3,2 \\
\hline Grupo 5 & 214 & 14,5 & 4 & 16,0 & 2 & 10,0 & 528 & 35,7 \\
\hline Grupo 6 & 134 & 9,2 & 0 & 0,0 & 2 & 10,0 & 23 & 1,5 \\
\hline Grupo 7 & 438 & 29,7 & 0 & 0,0 & 4 & 20,0 & 31 & 2,1 \\
\hline Grupo 8 & 33 & 2,2 & 0 & 0,0 & 0 & 0,0 & 5 & 0,3 \\
\hline Grupo 9 & 222 & 15,1 & 1 & 4,0 & 3 & 15,0 & 51 & 3,4 \\
\hline Outro & 186 & 12,6 & 13 & 52,0 & 6 & 30,0 & 627 & 42,4 \\
\hline Sem informação & 42 & 2,9 & 1 & 4,0 & 0 & 0,0 & 12 & 0,9 \\
\hline
\end{tabular}

masculino. As altas taxas de falta de informação quanto à escolaridade e da categoria "outros" quanto à ocupação impedem a descrição mais precisa destas características nos subgrupos do grupo A.

Quando as agressões ocorrem entre pais/responsáveis e filhos (Tabelas 4 e 5), crianças (0-11 anos) e adolescentes (12-19 anos) representam grande parte das vítimas $(34,3 \%$ e $33,8 \%$, respectivamente). No entanto, os adolescentes foram responsáveis pelas agressões em 3,8\% dos casos, enquanto os mais velhos ( $\geq 60$ anos) corresponderam a $5,2 \%$ das vítimas. Além disso, é possível destacar que: (1) quando os agressores são adultos ( $\geq 20$ anos), são em sua maioria homens em todas as faixas etárias, porém entre os agressores de ambos os sexos, predominam os mais jovens (43,7\% com idade entre $20-34$ anos) com porcentagens decrescentes quanto maior a idade, sendo freqüentemente solteiros entre os 
Características de agressores envolvidos em agressões familiares físicas (grupo $B ; n=213$ ), registradas em termos circunstanciados e inquéritos policiais na Delegacia de Defesa da Mulher de Araçatuba, São Paulo, Brasil, entre 2001 e 2005, segundo a faixa etária.

\begin{tabular}{|c|c|c|c|c|c|c|c|c|c|c|c|c|}
\hline \multirow[t]{2}{*}{ Características } & \multicolumn{2}{|c|}{$\begin{array}{l}12-19 \\
(n=8)\end{array}$} & \multicolumn{2}{|c|}{$\begin{array}{c}20-34 \\
(n=93)\end{array}$} & \multicolumn{2}{|c|}{$\begin{array}{c}35-44 \\
(n=63)\end{array}$} & \multicolumn{2}{|c|}{$\begin{array}{c}45-59 \\
(n=31)\end{array}$} & \multicolumn{2}{|c|}{$\begin{array}{c}\geq 60 \\
(n=7)\end{array}$} & \multicolumn{2}{|c|}{$\begin{array}{c}\text { Sem informação } \\
(n=11)\end{array}$} \\
\hline & $\mathrm{n}$ & $\%$ & $\mathrm{n}$ & $\%$ & $\mathrm{n}$ & $\%$ & $\mathbf{n}$ & $\%$ & $\mathrm{n}$ & $\%$ & $\mathrm{n}$ & $\%$ \\
\hline \multicolumn{13}{|l|}{ Gênero } \\
\hline Masculino & 3 & 37,5 & 56 & 60,3 & 44 & 69,8 & 24 & 77,5 & 6 & 85,7 & 9 & 81,8 \\
\hline Feminino & 5 & 62,5 & 37 & 39,7 & 19 & 30,2 & 7 & 22,5 & 1 & 14,3 & 2 & 18,2 \\
\hline \multicolumn{13}{|l|}{ Estado civil } \\
\hline Casado & 0 & 0,0 & 18 & 19,4 & 24 & 38,1 & 16 & 51,6 & 4 & 57,1 & 3 & 27,3 \\
\hline Solteiro & 8 & 100,0 & 65 & 69,8 & 20 & 31,7 & 10 & 32,2 & 0 & 0,0 & 6 & 54,5 \\
\hline Separado/Divorciado & 0 & 0,0 & 10 & 10,8 & 16 & 25,4 & 5 & 16,2 & 2 & 28,6 & 1 & 9,1 \\
\hline Viúvo & 0 & 0,0 & 0 & 0,0 & 3 & 4,8 & 0 & 0,0 & 1 & 14,3 & 1 & 9,1 \\
\hline Sem informação & 0 & 0,0 & 0 & 0,0 & 0 & 0,0 & 0 & 0,0 & 0 & 0,0 & 0 & 0,0 \\
\hline \multicolumn{13}{|l|}{ Escolaridade } \\
\hline Analfabeto & 0 & 0,0 & 2 & 2,2 & 3 & 4,8 & 2 & 6,4 & 0 & 0,0 & 0 & 0,0 \\
\hline Fundamental incompleto & 1 & 12,5 & 23 & 24,7 & 14 & 22,2 & 7 & 22,6 & 1 & 14,3 & 4 & 36,4 \\
\hline Fundamental completo & 2 & 25,0 & 4 & 4,3 & 4 & 6,3 & 4 & 12,9 & 0 & 0,0 & 0 & 0,0 \\
\hline Médio incompleto & 3 & 37,5 & 3 & 3,3 & 0 & 0,0 & 1 & 3,3 & 0 & 0,0 & 1 & 9,1 \\
\hline Médio completo & 0 & 0,0 & 10 & 10,8 & 7 & 11,2 & 1 & 3,3 & 0 & 0,0 & 0 & 0,0 \\
\hline Superior incompleto & 0 & 0,0 & 1 & 1,0 & 0 & 0,0 & 0 & 0,0 & 0 & 0,0 & 6 & 54,5 \\
\hline Superior completo & 0 & 0,0 & 0 & 0,0 & 1 & 1,6 & 2 & 6,4 & 0 & 0,0 & 0 & 0,0 \\
\hline Sem informação & 2 & 25,0 & 50 & 53,7 & 34 & 53,9 & 14 & 45,1 & 6 & 85,7 & 0 & 0,0 \\
\hline \multicolumn{13}{|l|}{ Ocupação } \\
\hline Grupo 0 & 0 & 0,0 & 0 & 0,0 & 0 & 0,0 & 0 & 0,0 & 0 & 0,0 & 0 & 0,0 \\
\hline Grupo 1 & 0 & 0,0 & 3 & 3,3 & 3 & 4,8 & 0 & 0,0 & 0 & 0,0 & 0 & 0,0 \\
\hline Grupo 2 & 0 & 0,0 & 1 & 1,0 & 2 & 3,1 & 2 & 6,4 & 0 & 0,0 & 0 & 0,0 \\
\hline Grupo 3 & 0 & 0,0 & 7 & 7,5 & 3 & 4,8 & 1 & 3,3 & 0 & 0,0 & 0 & 0,0 \\
\hline Grupo 4 & 0 & 0,0 & 0 & 0,0 & 0 & 0,0 & 0 & 0,0 & 0 & 0,0 & 0 & 0,0 \\
\hline Grupo 5 & 1 & 12,5 & 21 & 22,5 & 15 & 23,8 & 6 & 19,3 & 0 & 0,0 & 0 & 0,0 \\
\hline Grupo 6 & 0 & 0,0 & 5 & 5,4 & 3 & 4,8 & 3 & 9,6 & 2 & 28,6 & 0 & 0,0 \\
\hline Grupo 7 & 2 & 25,0 & 14 & 15,0 & 16 & 25,4 & 5 & 16,2 & 1 & 14,3 & 3 & 27,3 \\
\hline Grupo 8 & 0 & 0,0 & 0 & 0,0 & 2 & 3,1 & 0 & 0,0 & 0 & 0,0 & 0 & 0,0 \\
\hline Grupo 9 & 0 & 0,0 & 10 & 10,8 & 6 & 9,5 & 2 & 6,4 & 0 & 0,0 & 2 & 18,1 \\
\hline Outro & 5 & 62,5 & 28 & 30,2 & 13 & 20,7 & 12 & 38,8 & 4 & 57,1 & 3 & 27,3 \\
\hline Sem informação & 0 & 0,0 & 4 & 4,3 & 0 & 0,0 & 0 & 0,0 & 0 & 0,0 & 3 & 27,3 \\
\hline
\end{tabular}

mais jovens e freqüentemente casados entre os mais velhos; (2) quando as vítimas são crianças, a porcentagem de meninos é um pouco superior a de meninas (57,5\% e 42,5\% respectivamente), porém quando as vítimas são adolescentes, são em sua grande maioria meninas; (3) quando os agressores são adolescentes, são todos solteiros e na maioria mulheres; (4) quando as vítimas são adultas, são todas mulheres, solteiras, principalmente entre as mais jovens e separadas/ divorciadas ou viúvas, principalmente entre as mais velhas. As altas taxas de falta de informação quanto à escolaridade e da categoria "outro" quanto à ocupação impedem a descrição mais precisa destas características nos subgrupos do grupo B.

Quanto à agressão entre os demais membros da família (Tabelas 6 e 7), os agressores foram na maioria homens, enquanto as vítimas foram freqüentemente mulheres. Prevaleceram os agressores adultos jovens (52,6\% com 20-34 anos) e na faixa etária de $35-44$ anos $(21,5 \%)$, sendo os mais jovens freqüentemente solteiros e os mais velhos freqüentemente separados/divorciados. Quanto às vítimas, grande parte foi composta por adultos jovens (50,4\% com 20 -34 anos) e adolescentes $(18,5 \%)$, sendo os mais jovens freqüentemente solteiros e os mais velhos freqüentemente 
Características de vítimas envolvidas em agressões familiares físicas (grupo B; $n=213$ ), registradas em termos circunstanciados e inquéritos policiais na Delegacia de Defesa da Mulher de Araçatuba, São Paulo, Brasil, entre 2001 e 2005, segundo a faixa etária.

\begin{tabular}{|c|c|c|c|c|c|c|c|c|c|c|c|c|c|c|}
\hline \multirow[t]{2}{*}{ Características } & \multicolumn{2}{|c|}{$\begin{array}{c}0-11 \\
(n=73)\end{array}$} & \multicolumn{2}{|c|}{$\begin{array}{c}12-19 \\
(n=72)\end{array}$} & \multicolumn{2}{|c|}{$\begin{array}{c}20-34 \\
(n=15)\end{array}$} & \multicolumn{2}{|c|}{$\begin{array}{c}35-44 \\
(n=12)\end{array}$} & \multicolumn{2}{|c|}{$\begin{array}{c}45-59 \\
(n=30)\end{array}$} & \multicolumn{2}{|c|}{$\begin{array}{c}\geq 60 \\
(n=11)\end{array}$} & \multicolumn{2}{|c|}{$\begin{array}{c}\text { Sem informação } \\
(n=0)\end{array}$} \\
\hline & $\mathrm{n}$ & $\%$ & $\mathbf{n}$ & $\%$ & $\mathrm{n}$ & $\%$ & $\mathrm{n}$ & $\%$ & $\mathrm{n}$ & $\%$ & $\mathrm{n}$ & $\%$ & $\mathrm{n}$ & $\%$ \\
\hline \multicolumn{15}{|l|}{ Gênero } \\
\hline Masculino & 42 & 57,5 & 12 & 16,6 & 0 & 0,0 & 0 & 0,0 & 0 & 0,0 & 0 & 0,0 & 0 & 0,0 \\
\hline Feminino & 31 & 42,5 & 60 & 83,4 & 15 & 100,0 & 12 & 100,0 & 30 & 100,0 & 11 & 100,0 & 0 & 0,0 \\
\hline \multicolumn{15}{|l|}{ Estado civil } \\
\hline Casado & 0 & 0,0 & 0 & 0,0 & 1 & 6,7 & 3 & 25,0 & 5 & 16,6 & 1 & 9,1 & 0 & 0,0 \\
\hline Solteiro & 73 & 100,0 & 72 & 100,0 & 14 & 93,3 & 5 & 41,6 & 6 & 20,0 & 1 & 9,1 & 0 & 0,0 \\
\hline Separado/Divorciado & 0 & 0,0 & 0 & 0,0 & 0 & 0,0 & 3 & 25,0 & 10 & 33,4 & 2 & 18,2 & 0 & 0,0 \\
\hline Viúvo & 0 & 0,0 & 0 & 0,0 & 0 & 0,0 & 1 & 8,4 & 9 & 30,0 & 7 & 63,6 & 0 & 0,0 \\
\hline Sem informação & 0 & 0,0 & 0 & 0,0 & 0 & 0,0 & 0 & 0,0 & 0 & 0,0 & 0 & 0,0 & 0 & 0,0 \\
\hline \multicolumn{15}{|l|}{ Escolaridade } \\
\hline Analfabeto & 22 & 30,2 & 0 & 0,0 & 0 & 0,0 & 0 & 0,0 & 1 & 3,4 & 5 & 45,4 & 0 & 0,0 \\
\hline Fundamental incompleto & 32 & 43,8 & 4 & 5,6 & 1 & 6,7 & 1 & 8,4 & 8 & 26,7 & 2 & 18,2 & 0 & 0,0 \\
\hline Fundamental completo & 0 & 0,0 & 21 & 29,2 & 2 & 13,3 & 2 & 16,6 & 2 & 6,6 & 0 & 0,0 & 0 & 0,0 \\
\hline Médio incompleto & 0 & 0,0 & 13 & 18,0 & 1 & 6,7 & 1 & 8,4 & 0 & 0,0 & 0 & 0,0 & 0 & 0,0 \\
\hline Médio completo & 0 & 0,0 & 3 & 4,2 & 2 & 13,3 & 0 & 0,0 & 0 & 0,0 & 0 & 0,0 & 0 & 0,0 \\
\hline Superior incompleto & 0 & 0,0 & 1 & 1,4 & 2 & 13,3 & 0 & 0,0 & 0 & 0,0 & 0 & 0,0 & 0 & 0,0 \\
\hline Superior completo & 0 & 0,0 & 0 & 0,0 & 1 & 6,7 & 0 & 0,0 & 2 & 6,6 & 0 & 0,0 & 0 & 0,0 \\
\hline Sem informação & 19 & 26,0 & 30 & 41,6 & 6 & 40,0 & 8 & 66,6 & 17 & 56,7 & 4 & 36,4 & 0 & 0,0 \\
\hline \multicolumn{15}{|l|}{ Ocupação } \\
\hline Grupo 0 & 0 & 0,0 & 0 & 0,0 & 0 & 0,0 & 0 & 0,0 & 0 & 0,0 & 0 & 0,0 & 0 & 0,0 \\
\hline Grupo 1 & 0 & 0,0 & 0 & 0,0 & 0 & 0,0 & 0 & 0,0 & 2 & 6,6 & 0 & 0,0 & 0 & 0,0 \\
\hline Grupo 2 & 0 & 0,0 & 0 & 0,0 & 1 & 6,7 & 0 & 0,0 & 1 & 3,4 & 0 & 0,0 & 0 & 0,0 \\
\hline Grupo 3 & 0 & 0,0 & 0 & 0,0 & 0 & 0,0 & 1 & 8,4 & 0 & 0,0 & 0 & 0,0 & 0 & 0,0 \\
\hline Grupo 4 & 0 & 0,0 & 4 & 5,6 & 3 & 20,0 & 0 & 0,0 & 0 & 0,0 & 0 & 0,0 & 0 & 0,0 \\
\hline Grupo 5 & 0 & 0,0 & 2 & 2,8 & 3 & 20,0 & 7 & 58,3 & 8 & 26,6 & 0 & 0,0 & 0 & 0,0 \\
\hline Grupo 6 & 0 & 0,0 & 0 & 0,0 & 0 & 0,0 & 0 & 0,0 & 0 & 0,0 & 0 & 0,0 & 0 & 0,0 \\
\hline Grupo 7 & 0 & 0,0 & 0 & 0,0 & 0 & 0,0 & 0 & 0,0 & 1 & 3,4 & 0 & 0,0 & 0 & 0,0 \\
\hline Grupo 8 & 0 & 0,0 & 0 & 0,0 & 0 & 0,0 & 0 & 0,0 & 0 & 0,0 & 0 & 0,0 & 0 & 0,0 \\
\hline Grupo 9 & 0 & 0,0 & 1 & 1,4 & 2 & 13,3 & 0 & 0,0 & 0 & 0,0 & 0 & 0,0 & 0 & 0,0 \\
\hline Outro & 73 & 100,0 & 64 & 88,8 & 6 & 40,0 & 4 & 33,4 & 18 & 60,0 & 11 & 100,0 & 0 & 0,0 \\
\hline Sem informação & 0 & 0,0 & 1 & 1,4 & 0 & 0,0 & 0 & 0,0 & 0 & 0,0 & 0 & 0,0 & 0 & 0,0 \\
\hline
\end{tabular}

separados/divorciados. As altas taxas de falta de informação quanto à escolaridade e da categoria "outro" quanto à ocupação impedem a descrição mais precisa destas características nos subgrupos do grupo C.

A Tabela 8 mostra que as características dos laudos médicos foram semelhantes para os três grupos avaliados. As lesões em sua grande maioria eram leves e localizavam-se principalmente na cabeça e nos membros superiores, sendo as equimoses e as escoriações os tipos de lesões mais freqüentes. Poucas vítimas referiram ter procurado atendimento médico, sendo grande o número de laudos sem esta informação.
Buscaram atendimento quando acometidos por lesões leves: 11,3\% (grupo A); 8,1\% (grupo B); e 15,1\% (grupo C). Entretanto, quando atingidos gravemente recorreram aos serviços de saúde: $88,2 \%$ (grupo A); $100 \%$ (grupo B) e $100 \%$ (grupo C).

\section{Discussão}

As iniciativas de cooperação entre setores tão diversos como os da saúde, educação, serviços sociais, a justiça e a política são indispensáveis para resolver o problema da violência 1. Mas, 
Características de agressores envolvidos em agressões familiares físicas (grupo $C ; n=135$ ), registradas em termos circunstanciados e inquéritos policiais na Delegacia de Defesa da Mulher de Araçatuba, São Paulo, Brasil, entre 2001 e 2005, segundo a faixa etária.

\begin{tabular}{|c|c|c|c|c|c|c|c|c|c|c|c|c|}
\hline \multirow[t]{2}{*}{ Características } & \multicolumn{2}{|c|}{$\begin{array}{c}12-19 \\
(n=11)\end{array}$} & \multicolumn{2}{|c|}{$\begin{array}{c}20-34 \\
(n=71)\end{array}$} & \multicolumn{2}{|c|}{$\begin{array}{c}35-44 \\
(n=29)\end{array}$} & \multicolumn{2}{|c|}{$\begin{array}{c}45-59 \\
(n=15)\end{array}$} & \multicolumn{2}{|c|}{$\begin{array}{l}\geq 60 \\
(n=2)\end{array}$} & \multicolumn{2}{|c|}{$\begin{array}{c}\text { Sem informação } \\
(n=7)\end{array}$} \\
\hline & $\mathrm{n}$ & $\%$ & $\mathrm{n}$ & $\%$ & $\mathrm{n}$ & $\%$ & $\mathrm{n}$ & $\%$ & $\mathrm{n}$ & $\%$ & $\mathrm{n}$ & $\%$ \\
\hline \multicolumn{13}{|l|}{ Gênero } \\
\hline Masculino & 9 & 81,8 & 50 & 70,5 & 20 & 68,9 & 10 & 66,7 & 0 & 0,0 & 6 & 85,7 \\
\hline Feminino & 2 & 18,2 & 21 & 29,5 & 9 & 31,1 & 5 & 33,3 & 2 & 100,0 & 1 & 14,3 \\
\hline \multicolumn{13}{|l|}{ Estado civil } \\
\hline Casado & 0 & 0,0 & 10 & 14,0 & 8 & 27,6 & 4 & 26,7 & 1 & 50,0 & 3 & 42,8 \\
\hline Solteiro & 11 & 100,0 & 59 & 83,2 & 12 & 41,4 & 5 & 33,3 & 0 & 0,0 & 3 & 42,8 \\
\hline Separado/Divorciado & 0 & 0,0 & 1 & 1,4 & 9 & 31,0 & 6 & 40,0 & 1 & 50,0 & 0 & 0,0 \\
\hline Viúvo & 0 & 0,0 & 0 & 0,0 & 0 & 0,0 & 0 & 0,0 & 0 & 0,0 & 0 & 0,0 \\
\hline Sem informação & 0 & 0,0 & 1 & 1,4 & 0 & 0,0 & 0 & 0,0 & 0 & 0,0 & 1 & 14,3 \\
\hline \multicolumn{13}{|l|}{ Escolaridade } \\
\hline Analfabeto & 1 & 9,1 & 0 & 0,0 & 1 & 3,5 & 0 & 0,0 & 0 & 0,0 & 1 & 14,3 \\
\hline Fundamental incompleto & 0 & 0,0 & 19 & 26,7 & 6 & 20,6 & 2 & 13,3 & 0 & 0,0 & 0 & 0,0 \\
\hline Fundamental completo & 3 & 27,3 & 8 & 11,3 & 0 & 0,0 & 0 & 0,0 & 0 & 0,0 & 0 & 0,0 \\
\hline Médio incompleto & 5 & 45,4 & 1 & 1,4 & 1 & 3,5 & 1 & 6,7 & 0 & 0,0 & 1 & 14,3 \\
\hline Médio completo & 1 & 9,1 & 7 & 9,8 & 3 & 10,3 & 2 & 13,3 & 1 & 50,0 & 0 & 0,0 \\
\hline Superior incompleto & 0 & 0,0 & 3 & 4,3 & 0 & 0,0 & 0 & 0,0 & 0 & 0,0 & 0 & 0,0 \\
\hline Superior completo & 0 & 0,0 & 0 & 0,0 & 1 & 3,5 & 0 & 0,0 & 0 & 0,0 & 0 & 0,0 \\
\hline Sem informação & 1 & 9,1 & 33 & 46,5 & 17 & 58,6 & 10 & 66,7 & 1 & 50,0 & 5 & 71,4 \\
\hline \multicolumn{13}{|l|}{ Ocupação } \\
\hline Grupo 0 & 0 & 0,0 & 1 & 1,4 & 0 & 0,0 & 0 & 0,0 & 0 & 0,0 & 0 & 0,0 \\
\hline Grupo 1 & 0 & 0,0 & 1 & 1,4 & 4 & 13,7 & 2 & 13,3 & 0 & 0,0 & 1 & 14,3 \\
\hline Grupo 2 & 1 & 9,1 & 0 & 0,0 & 2 & 6,9 & 0 & 0,0 & 0 & 0,0 & 0 & 0,0 \\
\hline Grupo 3 & 0 & 0,0 & 1 & 1,4 & 2 & 6,9 & 1 & 6,7 & 0 & 0,0 & 0 & 0,0 \\
\hline Grupo 4 & 0 & 0,0 & 2 & 2,9 & 1 & 3,5 & 0 & 0,0 & 0 & 0,0 & 0 & 0,0 \\
\hline Grupo 5 & 0 & 0,0 & 13 & 18,3 & 3 & 10,3 & 1 & 6,7 & 0 & 0,0 & 0 & 0,0 \\
\hline Grupo 6 & 0 & 0,0 & 8 & 11,3 & 1 & 3,5 & 0 & 0,0 & 0 & 0,0 & 1 & 14,3 \\
\hline Grupo 7 & 1 & 9,1 & 15 & 21,1 & 6 & 20,6 & 3 & 20,0 & 0 & 0,0 & 1 & 14,3 \\
\hline Grupo 8 & 0 & 0,0 & 0 & 0,0 & 0 & 0,0 & 0 & 0,0 & 0 & 0,0 & 0 & 0,0 \\
\hline Grupo 9 & 2 & 18,2 & 8 & 11,3 & 1 & 3,5 & 2 & 13,3 & 0 & 0,0 & 0 & 0,0 \\
\hline Outro & 7 & 63,6 & 21 & 29,5 & 9 & 31,1 & 5 & 33,3 & 2 & 100,0 & 1 & 14,3 \\
\hline Sem informação & 0 & 0,0 & 1 & 1,4 & 0 & 0,0 & 1 & 6,7 & 0 & 0,0 & 3 & 42,8 \\
\hline
\end{tabular}

para que se possa planejar e desenvolver ações voltadas à prevenção dos casos e assistência às vítimas de violência familiar, são necessários dados que permitam visualizar e compreender a situação.

Embora não seja intenção desse estudo estereotipar os sujeitos envolvidos com esse tipo de ocorrência, até porque o mesmo restringiuse aos casos denunciados, sua realização tornou possível a observação de alguns atributos comuns entre eles.

Quanto às características das agressões, de forma geral, o fato de ocorrerem com mais freqüência aos sábados e domingos, no horário noturno, pode ser atribuído à maior permanência dos membros da família em suas casas aos finais de semana e durante a noite. Da mesma forma, estudo realizado por Deslandes 6 junto a um serviço de emergência hospitalar constatou a predominância de agressões durante o final de semana, no período das 20:00 às 8:00 horas.

Prevaleceram as ocorrências entre casais, sendo os homens solteiros os agressores mais freqüentes em comparação com os casados ou separados/divorciados. Este dado sugere que as relações mais estáveis envolvem menos casos de violência física. Num estudo realizado em hospitais públicos do Rio de Janeiro, Brasil, 
Características de vítimas envolvidas em agressões familiares físicas (grupo $C_{;} n=135$ ), registradas em termos circunstanciados e inquéritos policiais na Delegacia de Defesa da Mulher de Araçatuba, São Paulo, Brasil, entre 2001 e 2005, segundo a faixa etária.

\begin{tabular}{|c|c|c|c|c|c|c|c|c|c|c|c|c|c|c|}
\hline \multirow[t]{2}{*}{ Características } & \multicolumn{2}{|c|}{$\begin{array}{c}0-11 \\
(n=4)\end{array}$} & \multicolumn{2}{|c|}{$\begin{array}{c}12-19 \\
(n=25)\end{array}$} & \multicolumn{2}{|c|}{$\begin{array}{c}20-34 \\
(n=68)\end{array}$} & \multicolumn{2}{|c|}{$\begin{array}{c}35-44 \\
(n=15)\end{array}$} & \multicolumn{2}{|c|}{$\begin{array}{c}45-59 \\
(n=14)\end{array}$} & \multicolumn{2}{|c|}{$\begin{array}{c}\geq 60 \\
(n=8)\end{array}$} & \multicolumn{2}{|c|}{$\begin{array}{c}\text { Sem informação } \\
(n=1)\end{array}$} \\
\hline & $\mathrm{n}$ & $\%$ & $n$ & $\%$ & $\mathrm{n}$ & $\%$ & $\mathrm{n}$ & $\%$ & $\mathrm{n}$ & $\%$ & $\mathbf{n}$ & $\%$ & $\mathbf{n}$ & $\%$ \\
\hline \multicolumn{15}{|l|}{ Gênero } \\
\hline Masculino & 3 & 75,0 & 3 & 12,0 & 2 & 3,0 & 0 & 0,0 & 0 & 0,0 & 0 & 0,0 & 0 & 0,0 \\
\hline Feminino & 1 & 25,0 & 22 & 88,0 & 66 & 97,0 & 15 & 100,0 & 14 & 100,0 & 8 & 100,0 & 1 & 100,0 \\
\hline \multicolumn{15}{|l|}{ Estado civil } \\
\hline Casado & 0 & 0,0 & 0 & 0,0 & 8 & 11,8 & 2 & 13,4 & 3 & 21,5 & 0 & 0,0 & 1 & 100,0 \\
\hline Solteiro & 4 & 100,0 & 25 & 100,0 & 55 & 80,8 & 8 & 53,4 & 4 & 28,5 & 0 & 0,0 & 0 & 0,0 \\
\hline Separado/Divorciado & 0 & 0,0 & 0 & 0,0 & 5 & 7,4 & 4 & 26,6 & 4 & 28,5 & 0 & 0,0 & 0 & 0,0 \\
\hline Viúvo & 0 & 0,0 & 0 & 0,0 & 0 & 0,0 & 1 & 6,6 & 3 & 21,5 & 8 & 100,0 & 0 & 0,0 \\
\hline Sem informação & 0 & 0,0 & 0 & 0,0 & 0 & 0,0 & 0 & 0,0 & 0 & 0,0 & 0 & 0,0 & 0 & 0,0 \\
\hline \multicolumn{15}{|l|}{ Escolaridade } \\
\hline Analfabeto & 2 & 50,0 & 0 & 0,0 & 0 & 0,0 & 0 & 0,0 & 1 & 7,1 & 0 & 0,0 & 0 & 0,0 \\
\hline Fundamental incompleto & 1 & 25,0 & 5 & 20,0 & 12 & 17,7 & 3 & 20,0 & 2 & 14,3 & 3 & 37,5 & 0 & 0,0 \\
\hline Fundamental completo & 0 & 0,0 & 5 & 20,0 & 7 & 10,3 & 2 & 13,4 & 1 & 7,1 & 0 & 0,0 & 0 & 0,0 \\
\hline Médio incompleto & 0 & 0,0 & 4 & 16,0 & 2 & 2,9 & 0 & 0,0 & 2 & 14,3 & 0 & 0,0 & 0 & 0,0 \\
\hline Médio completo & 0 & 0,0 & 3 & 12,0 & 8 & 11,8 & 1 & 6,6 & 3 & 21,5 & 0 & 0,0 & 0 & 0,0 \\
\hline Superior incompleto & 0 & 0,0 & 0 & 0,0 & 3 & 4,4 & 0 & 0,0 & 0 & 0,0 & 0 & 0,0 & 0 & 0,0 \\
\hline Superior completo & 0 & 0,0 & 0 & 0,0 & 1 & 1,5 & 1 & 6,6 & 0 & 0,0 & 0 & 0,0 & 0 & 0,0 \\
\hline Sem informação & 1 & 25,0 & 8 & 32,0 & 35 & 51,4 & 8 & 53,4 & 5 & 35,7 & 5 & 62,5 & 1 & 100,0 \\
\hline \multicolumn{15}{|l|}{ Ocupação } \\
\hline Grupo 0 & 0 & 0,0 & 0 & 0,0 & 0 & 0,0 & 0 & 0,0 & 0 & 0,0 & 0 & 0,0 & 0 & 0,0 \\
\hline Grupo 1 & 0 & 0,0 & 0 & 0,0 & 2 & 2,9 & 2 & 13,4 & 2 & 14,3 & 0 & 0,0 & 0 & 0,0 \\
\hline Grupo 2 & 0 & 0,0 & 0 & 0,0 & 2 & 2,9 & 1 & 6,6 & 1 & 7,1 & 0 & 0,0 & 1 & 100,0 \\
\hline Grupo 3 & 0 & 0,0 & 0 & 0,0 & 3 & 4,4 & 0 & 0,0 & 3 & 21,4 & 0 & 0,0 & 0 & 0,0 \\
\hline Grupo 4 & 0 & 0,0 & 0 & 0,0 & 5 & 7,4 & 0 & 0,0 & 0 & 0,0 & 0 & 0,0 & 0 & 0,0 \\
\hline Grupo 5 & 0 & 0,0 & 5 & 20,0 & 21 & 30,9 & 6 & 40,0 & 2 & 14,3 & 0 & 0,0 & 0 & 0,0 \\
\hline Grupo 6 & 0 & 0,0 & 0 & 0,0 & 4 & 5,9 & 0 & 0,0 & 0 & 0,0 & 0 & 0,0 & 0 & 0,0 \\
\hline Grupo 7 & 0 & 0,0 & 0 & 0,0 & 2 & 2,9 & 0 & 0,0 & 0 & 0,0 & 0 & 0,0 & 0 & 0,0 \\
\hline Grupo 8 & 0 & 0,0 & 0 & 0,0 & 0 & 0,0 & 0 & 0,0 & 0 & 0,0 & 0 & 0,0 & 0 & 0,0 \\
\hline Grupo 9 & 0 & 0,0 & 1 & 4,0 & 3 & 4,4 & 0 & 0,0 & 0 & 0,0 & 0 & 0,0 & 0 & 0,0 \\
\hline Outro & 4 & 100,0 & 18 & 72,0 & 25 & 36,8 & 6 & 40,0 & 6 & 42,9 & 8 & 100,0 & 0 & 0,0 \\
\hline Sem informação & 0 & 0,0 & 1 & 4,0 & 1 & 1,5 & 0 & 0,0 & 0 & 0,0 & 0 & 0,0 & 0 & 0,0 \\
\hline
\end{tabular}

com mulheres vítimas de violência doméstica a maioria das agressões $(56,9 \%)$ foi atribuída ao marido, sendo observados também, casos de violência cometida por ex-maridos $(6,9 \%)$ e namorados $(4,2 \%) 7$. No tocante às ocorrências entre os sujeitos do grupo B, o pai destacou-se como o principal agressor, seguido pela mãe e filhos(as), sugerindo que a violência física é mais freqüentemente utilizada pelos pais, do que pelas mães para a resolução de conflitos na relação com os filhos. Entre as agressões distribuídas no grupo C, o (a) irmão(ã) foi o agente mais citado em meio aos demais familiares, como tios(as), cunhados(as), primos(as).
Acerca dos motivos da agressão, os chamados "desentendimentos domésticos" que se referem às discussões ligadas à convivência entre vítima e agressor (educação dos filhos; limpeza e organização da casa; divergência quanto à distribuição das tarefas domésticas) prevaleceram em todos os grupos, fato compreensível se for considerado que o lar foi o local de maior ocorrência das agressões. Para Santin et al. 8, são os fatos corriqueiros e banais os responsáveis pela conversão de agressividade em agressão. Complementa ainda que o sentimento de posse do homem em relação à mulher e filhos, bem como a impunidade, são fatores que generalizam a violência. 
Características das 1.844 agressões familiares físicas registradas em termos circunstanciados e inquéritos policiais na Delegacia de Defesa da Mulher de Araçatuba, São Paulo, Brasil, entre 2001 e 2005, segundo grupos de parentesco.

\begin{tabular}{|c|c|c|c|c|c|c|}
\hline \multirow[t]{2}{*}{ Características } & \multicolumn{2}{|c|}{ Grupo A } & \multicolumn{2}{|c|}{ Grupo B } & \multicolumn{2}{|c|}{ Grupo C } \\
\hline & $\mathrm{n}$ & $\%$ & $\mathrm{n}$ & $\%$ & $\mathrm{n}$ & $\%$ \\
\hline \multicolumn{7}{|l|}{ Laudo médico } \\
\hline Presentes & 930 & 62,2 & 136 & 63,8 & 93 & 68,8 \\
\hline Ausentes & 566 & 37,8 & 77 & 36,2 & 42 & 31,2 \\
\hline Total & 1.496 & 100,0 & 213 & 100,0 & 135 & 100,0 \\
\hline \multicolumn{7}{|l|}{ Tipos de lesões * } \\
\hline Edema & 192 & 7,6 & 12 & 4,7 & 15 & 6,7 \\
\hline Equimose & 1.075 & 42,8 & 141 & 54,8 & 74 & 33,3 \\
\hline Escoriação & 763 & 30,4 & 52 & 20,2 & 84 & 37,8 \\
\hline Ferimento contuso & 56 & 2,3 & 14 & 5,4 & 8 & 3,6 \\
\hline Ferimento corto-contuso & 82 & 3,3 & 6 & 2,4 & 9 & 4,0 \\
\hline Ferimento inciso & 30 & 1,2 & 2 & 0,8 & 2 & 1,0 \\
\hline Fratura & 22 & 0,8 & 1 & 0,4 & 5 & 2,3 \\
\hline Hematoma & 134 & 5,3 & 12 & 4,7 & 3 & 1,4 \\
\hline Outros & 155 & 6,2 & 17 & 6,6 & 22 & 9,9 \\
\hline Total & 2.509 & 100,0 & 257 & 100,0 & 222 & 100,0 \\
\hline \multicolumn{7}{|l|}{ Localização das lesões ** } \\
\hline Cabeça & 824 & 35,9 & 84 & 29,4 & 81 & 33,7 \\
\hline Pescoço & 61 & 2,7 & 11 & 3,9 & 30 & 12,6 \\
\hline Membros superiores & 778 & 33,9 & 81 & 28,3 & 74 & 30,8 \\
\hline Tronco & 379 & 16,6 & 60 & 20,9 & 14 & 5,9 \\
\hline Membros inferiores & 251 & 10,9 & 50 & 17,5 & 41 & 17,0 \\
\hline Total & 2.293 & 100,0 & 286 & 100,0 & 240 & 100,0 \\
\hline \multicolumn{7}{|l|}{ Classificação legal das lesões } \\
\hline Leve & 880 & 94,6 & 123 & 90,5 & 86 & 92,4 \\
\hline Grave & 17 & 1,9 & 2 & 1,5 & 4 & 4,3 \\
\hline Prejudicada & 33 & 3,5 & 11 & 8,0 & 3 & 3,3 \\
\hline Total & 930 & 100,0 & 136 & 100,0 & 93 & 100,0 \\
\hline \multicolumn{7}{|c|}{ Procura por atendimento médico } \\
\hline Sim & 197 & 13,2 & 23 & 10,9 & 21 & 15,6 \\
\hline Não & 523 & 34,9 & 76 & 35,6 & 24 & 17,8 \\
\hline Sem informação & 776 & 51,9 & 114 & 53,5 & 90 & 66,6 \\
\hline Total & 1.496 & 100,0 & 213 & 100,0 & 135 & 100,0 \\
\hline
\end{tabular}

* Em alguns casos a vítima apresentou mais de um tipo de lesão;

** Em alguns casos, a vítima apresentou mais de uma lesão no mesmo local.

Outro agravante atribuído às situações de abuso é o consumo de drogas. Brookoff et al. 9 verificaram que o uso de substâncias psicoativas, tanto pelo autor quanto pela vítima, esteve presente em até $92 \%$ dos casos de violência doméstica atendidos pela polícia do Tennessee, Estados Unidos, à época do estudo. Na presente pesquisa, a ingestão de bebidas alcoólicas pelo agressor foi relatada em um quarto dos casos, enquanto que o uso de drogas ilícitas foi limitado. $\mathrm{O}$ baixo índice referente a este último tipo de droga pode estar relacionado justamente ao seu caráter ilícito, ou seja, é possível a vítima durante o de- poimento, omitir a informação sobre a presença de entorpecentes, numa tentativa de proteger o causador da agressão.

Quanto às características dos agressores pertencentes ao grupo A, podemos notar altas taxas de homens, adultos jovens, com ocupações referentes aos serviços braçais, que se declararam solteiros. Interessante ressaltar que, mesmo de forma discreta, as mulheres também aparecem como agressoras nas situações de violência entre casais, distribuindo-se, entretanto, de forma semelhante entre casadas e solteiras. A diferença entre o número de vítimas e autores do mesmo 
gênero deve-se ao registro de violência entre pares do mesmo sexo na amostra.

Grande parte dos agressores está distribuída entre as categorias "analfabeto" e "Ensino Fundamental”, no entanto, mais da metade dos registros não apresenta a informação sobre a escolaridade do autor, possivelmente a vítima não tenha sido questionada a respeito, ou mesmo se questionada, esta não soube informá-la. Desta forma, o elevado percentual de falta de informação quanto à escolaridade impede a descrição mais detalhada dessa característica.

A baixa escolaridade e o conseqüente exercício de ocupação não especializada podem ser reflexos da pobreza. Marinheiro 10 afirma que a violência doméstica incide, sobretudo, naqueles níveis sociais de baixa renda, devido a uma maior dificuldade financeira e desestruturação familiar, o que favoreceria os comportamentos agressivos. Entretanto, devemos analisar com prudência esta afirmação, pois a maior prevalência de violência nas classes sociais menos favorecidas pode estar relacionada ao fato de que as pessoas mais pobres tendem a denunciar mais, dando visibilidade ao problema geralmente ocultado entre os mais abastados economicamente.

Resultados diversos foram encontrados por Kronbauer \& Meneghel 11 em trabalho desenvolvido junto às usuárias de uma unidade básica de saúde, onde os homens mais velhos e desocupados compuseram perfil do agente. A baixa escolaridade também foi característica descrita pelos autores. Gianini et al. 12, analisando as características das vítimas de violência física atendidas em um serviço de saúde, afirmam que, em relação ao estado civil, homens solteiros apresentam maiores riscos de se envolverem com agressão devido aos hábitos noturnos e solitários. Importante salientar que os autores diferenciaram os declarados solteiros, daqueles que afirmaram viver em união informal.

A respeito das características das vítimas, ainda no grupo A, os resultados do presente estudo estão em concordância com outros trabalhos, como o realizado por Jong 13 ao analisar ocorrências policiais. A autora constatou que $29,4 \%$ das vítimas estavam incluídas na faixa de 21-30 anos, enquanto que Tavares 14 apontou como mais prevalente a violência na idade entre 31-40 anos, em meio às usuárias de um serviço de saúde.

A respeito da escolaridade, pode-se notar que em quase metade das ocorrências, este item é omitido. Provavelmente isso se deve à atitude da escrivã policial, que ao elaborar a ocorrência deixa de questionar o assunto à vítima.

Os dados do grupo B permitem formular hipóteses quanto à ocorrência de violência contra crianças e idosos, cometida por seus responsá- veis. Entretanto, não são claros quanto à identificação dos possíveis pares agressor-vítima. Assim, muitas vítimas são mulheres com mais de 19 anos que podem ter sido agredidas por seus filhos adolescentes ou adultos jovens. Também avós, como responsáveis podem ter agredido netos. Já no grupo A, a violência entre casais, por óbvio, não acontece na infância, atinge alta prevalência na idade adulta e decai gradativamente com o aumentar da idade.

Diferentemente dos estudos de Jong 13 e Tavares 14 que apresentaram a maioria de vítimas casadas, a presente pesquisa demonstrou a maior prevalência de mulheres solteiras. Comparandose esse dado à realidade de que o companheiro é na maior parte dos casos o agressor, pode-se concluir que muitas ditas "solteiras", na realidade vivem em união informal. Este tipo de relação tende a ser mais conflituosa e instável 15 .

Quanto à ocupação das mesmas, foi predominante o número que se declarou "do lar", "estudante", "aposentada ou pensionista”, e "economia informal”, condições não classificadas pela CBO 5. Em seguida, aparece o grupo 5, abrangendo profissões como "empregada doméstica", "cabeleireira", "vendedora” etc. A este respeito, Deslandes et al. 7 verificaram em estudo realizado junto às mulheres atendidas em dois hospitais que a maior parte das vítimas estava desempregada (23,2\%) à época da agressão e algumas desempenhavam somente as funções do lar $(16,1 \%)$. Os altos índices de pessoas violentadas que não exercem atividade remunerada podem explicar, em parte, a permanência das mesmas junto ao agressor, ou seja, são dependentes economicamente dele.

As ocorrências do grupo C não apresentam muita variação em relação ao perfil geral das agressões estudadas nessa pesquisa. Pode-se destacar, mesmo que sutilmente, uma maior distribuição de suas vítimas, geralmente jovens, entre as ocupações profissionais, o que pode significar, ao contrário dos demais grupos, uma não dependência financeira dos sujeitos deste, em relação a seus agressores.

A respeito das características das seqüelas da agressão, periciadas pelos médicos legistas do Instituto Médico Legal (IML) do município onde se realizou o estudo, pode-se observar que algumas ocorrências não apresentam o laudo do exame. Isso pode ser explicado pelo não comparecimento das vítimas ao instituto para submeter-se à perícia, possivelmente porque muitas se arrependem de ter realizado a ocorrência; se inibem frente à consulta médica, ou mesmo, encontram dificuldade de acesso ao local, já que o IML não se encontra próximo à delegacia pesquisada. Além disso, nos casos onde a vítima depende di- 
retamente de terceiro para conduzi-la ao exame, a ausência da mesma pode ser mais prevalente.

Conhecer a "geografia" mais comum das lesões numa situação de violência intrafamiliar é importante para que o profissional de saúde possa suspeitar diante de casos não declarados 6 . O local preferencial das lesões encontrado no presente estudo (região de cabeça e pescoço e membros superiores) está em concordância com o relatado na literatura. Sabe-se que a cabeça, normalmente constitui o sítio de maior ocorrência de ferimentos nestas situações 7,13,16,17,18, assim, os membros superiores provavelmente devem ter servido de anteparo para as vítimas se defenderem de agressões dirigidas ao rosto delas.

Entre as lesões físicas provocadas nessas situações, prevaleceram as equimoses e as escoriações. A agressão, na maioria dos casos, ocorreu sem ajuda de armas convencionais, ou seja, o agente valeu-se do seu próprio corpo (socos, pontapés, tapas, empurrões) para prejudicar a vítima.

No que se refere à classificação legal das lesões, a predominância de danos considerados "leves" pelos peritos pode contribuir para a explicação da procura relativamente baixa das vítimas pelos setores de saúde.

Bruschi et al. 19 ao investigarem os locais mais procurados por vítimas de violência doméstica verificaram que, dentre as instituições, as delegacias de polícia aparecem em primeiro lugar (36,8\%), enquanto que os serviços de saúde só foram buscados em 5,3\% dos casos. Da mesma forma, Schraiber et al. 20 relata que 31,3\% das vítimas pesquisadas por ela procuram a polícia, ao passo que somente $15,6 \%$ recorrem ao serviço de saúde. Isso pode significar que as lesões não representaram um problema grave para as vítimas ou que as mesmas não consideram o setor de saúde como competente para lidar com a violência.

\section{Conclusões}

Este estudo nos permite concluir que nas ocorrências de violência familiar registradas no Município de Araçatuba, entre os anos de 2001 e 2005, predominaram como agressores o companheiro atual e o cônjuge para o grupo A, os pais para o grupo B e o(a) irmão(a) para o grupo C.

Quanto ao dia, horário e local de maior ocorrência houve maior freqüência de agressões entre casais nos finais de semana, sem que este padrão tenha se repetido nas agressões entre pais e filhos, ocorrendo principalmente em casa, no período das 12:00 às 24:00 horas nos três grupos.

No que se refere aos motivos atribuídos às agressões, prevaleceram os desentendimentos domésticos em todos os grupos. Cerca de um quarto a um quinto dos agressores estavam alcoolizados no momento da agressão, nas ocorrências entre casais, pais e filhos e demais responsáveis.

Quanto à agressão entre casais, a maioria dos agressores foi composta por homens, solteiros (companheiros, ex-companheiros, namorados e ex-namorados), jovens, enquanto que entre as vítimas, prevaleceram as mulheres de mesmas características. Existiram uniões afetivas de pessoas do mesmo sexo.

Quando as agressões ocorreram entre pais/ responsáveis e filhos, as crianças e adolescentes representaram grande parte das vítimas, sendo a porcentagem de meninos um pouco superior a de meninas, porém quando as vítimas foram adolescentes, eram em sua grande maioria, meninas. Os adolescentes foram responsáveis pelas agressões em alguns casos, e os idosos também foram vitimados.

Quanto à agressão entre os demais membros da família, os agressores foram na maioria homens, também jovens, enquanto as vítimas foram freqüentemente mulheres, adolescentes $\mathrm{e}$ adultas.

As características dos laudos médicos foram semelhantes para os três grupos avaliados. As lesões foram, em maioria, leves e localizavam-se principalmente na cabeça e nos membros superiores, sendo as equimoses e as escoriações os tipos de lesões mais freqüentes. Poucas vítimas referiram ter procurado atendimento médico, sendo grande o número de laudos sem esta informação. 


\section{Resumo}

Este estudo examinou agressões físicas intrafamiliares registradas em Araçatuba, São Paulo, Brasil, durante 2001-2005. São descritas características sócio-demográficas de agressores e vítimas; parentesco; local, horário, dia da semana e motivos das agressões; tipos de lesão e uso de álcool/drogas pelos agressores. Das 7.750 ocorrências, 1.844 estavam relacionadas à agressão física intrafamiliar: $81,1 \%$ envolvendo parceiros íntimos (grupo A), 11,6\% pais/responsáveis e filhos (grupo B) e 7,3\% outros familiares (grupo C). Nos três grupos, as agressões ocorreram principalmente em casa, sendo os agressores predominantemente do sexo masculino. No grupo A as agressões ocorreram principalmente nos finais de semana (38,9\%), sendo o ciúme, motivo freqüentemente relatado (21,5\%). No grupo B, crianças/ adolescentes constituíram $68,1 \%$ das vítimas, predominando as meninas entre os adolescentes; $3,8 \%$ dos agressores eram adolescentes, e 5,2\% das vítimas tinham idade $\geq 60$ anos. Nos três grupos, predominaram lesões leves, principalmente equimoses e escoriações, acometendo cabeça e membros superiores. Os agressores estavam freqüentemente alcoolizados: $26,8 \%$ (grupo A), 21,6\% (grupo B), e 17,1\% (grupo C). O uso de drogas foi provavelmente subestimado nos três grupos (2,2\%, $1,8 \%$ e $4,5 \%$ respectivamente).

Violência Doméstica; Agressão; Comportamento; Ferimentos e Lesões

\section{Referências}

1. Organización Panamericana de la Salud. Informe mundial sobre la violencia y la salud. Washington DC: Organización Panamericana de la Salud; 2003.

2. Schraiber LB, d'Oliveira AFLP. Violência contra mulheres: interfaces com a saúde. Interface Comun Saúde Educ 1999; 3:11-26.

3. Brasil. Lei $\mathrm{n}^{\circ} .9 .099$ de 26 de setembro de 1995 Dispõe sobre os Juizados Especiais Criminais e dá outras providências. Diário Oficial da União 1995; 27 set.

4. Mirabete JF. Manual de direito penal: parte especial. São Paulo: Editora Atlas; 2006.

5. Brasil. Ministério do Trabalho e do Emprego. Classificação brasileira das ocupações, 2002. http:// www.mte.cbo.gov.br/busca.asp (acessado em 12/ Out/2006)

6. Deslandes SF. O atendimento às vítimas de violência na emergência: "prevenção numa hora dessas?”. Ciênc Saúde Coletiva 1999; 4:81-94.

\section{Colaboradores}

A. P. Dossi participou da idealização do projeto, realizou o levantamento bibliográfico, a coleta e análise dos dados, bem como a redação do artigo. O. Saliba participou da idealização do projeto, análise dos dados coletados, orientação estatística e redação do artigo. C. A. S. Garbin colaborou na idealização do projeto, orientou o levantamento bibliográfico, a coleta e análise dos dados, assim como a redação do artigo. A. J. I. Garbin contribuiu na análise dos dados coletados orientando a etapa estatística, além de contribuir para a redação do artigo.

\section{Agradecimentos}

A Coordenação de Aperfeiçoamento de Pessoal de Nível Superior (CAPES) pelo apoio financeiro. À delegada de polícia da Delegacia de Defesa da Mulher de Araçatuba, Dra. Ana Lúcia Souza Marques, por permitir a realização da pesquisa na referida unidade.
7. Deslandes SF, Gomes R, Silva CMFP. Caracterização dos casos de violência doméstica contra a mulher atendidos em dois hospitais públicos do Rio de Janeiro. Cad Saúde Pública 2000; 16:129-37.

8. Santin JR, Guazzelli MP, Campana JB, Campana LB. Violência doméstica: como legislar o silêncio: estudo interdisciplinar na realidade local. Revista Justiça do Direito 2002; 1:79-97.

9. Brookoff D, O'Brien KK, Cook CS, Thompson TD, Williams C. Characteristics of participants in domestic violence. Assessment at the scene of domestic assault. JAMA 1997; 277:1369-73.

10. Marinheiro ALV. Violência doméstica: prevalência entre mulheres usuárias de um serviço de saúde de Ribeirão Preto [Dissertação de Mestrado]. Ribeirão Preto: Faculdade de Medicina de Ribeirão Preto, Universidade de São Paulo; 2003.

11. Kronbauer JFD, Meneghel SN. Perfil da violência de gênero perpetrada por companheiro. Rev Saúde Pública 2005; 39:695-701. 
12. Gianini RJ, Litivoc J, Eluf Neto J. Agressão física e classe social. Rev Saúde Pública 1999; 33:180-6.

13. Jong LC. Perfil epidemiológico da violência doméstica contra a mulher em cidade do interior paulista [Dissertação de Mestrado]. São Paulo: Faculdade de Saúde Pública, Universidade de São Paulo; 2000.

14. Tavares DMC. Violência doméstica: uma questão de saúde pública [Dissertação de Mestrado]. São Paulo: Faculdade de Saúde Pública, Universidade de São Paulo; 2000.

15. Scott E. Canada's family violence initiative: partnerships. Cad Saúde Pública 1994; 10 Suppl 1: S218-22.

16. Jaramillo DE, Uribe TM. Rol del personal en la atención a las mujeres maltratadas. Invest Educ Enferm 2001; 19:38-45.
17. Schraiber LB, D'Oliveira AFPL, França-Junior I, Pinho AA. Violência contra a mulher: estudo em uma unidade de atenção primária à saúde. Rev Saúde Pública 2002; 36:470-7.

18. Garbin CAS, Garbin AJI, Dossi AP, Dossi MO. Violência doméstica: análise das lesões em mulheres. Cad Saúde Pública 2006; 22:2567-73.

19. Bruschi A, Paula CS, Bordin IAS. Prevalência e procura de ajuda na violência conjugal física ao longo da vida. Rev Saúde Pública 2006; 40:256-64.

20. Schraiber LB, d'Oliveira AFPL, Couto MT, Figueiredo WS. Violência dói e não é direito: a violência contra a mulher, a saúde e os direitos humanos. São Paulo: Editora da Universidade Estadual Paulista; 2005.

Recebido em 29/Nov/2006

Versão final reapresentada em 02/Jan/2008

Aprovado em 14/Jan/2008 